OUR ASTRONOMICAL COLUMN.

Holmes' Comet (I899 d).

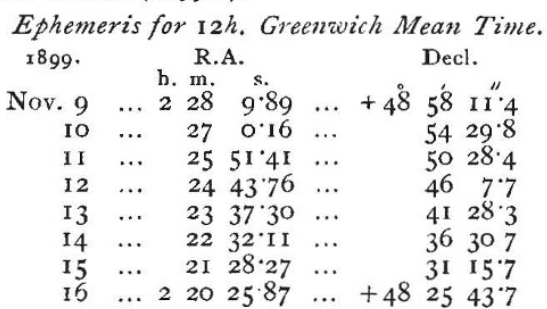

Comet Giacobini ( $1899 e$ ).

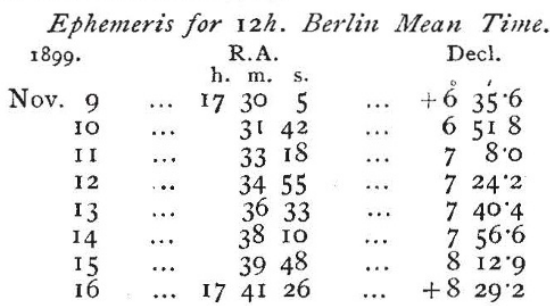

The Coming Meteor Shower.-Much has recently been written respecting the necessary preparations for obtaining photographic record of the Leonids, but hitherto these instructions have only taken into consideration the determination of the position and appearance of the meteor trail. There must be many, however, who are in a position to attempt to obtain a record of the composition of the meteorites. The only additional apparatus will be either a prism or a diffraction grating. After the camera has been focussed, the prism or grating can be very simply attached to the hood of the lens, and the whole then constitutes a small prismatic camera which will give the spectrum of any meteor whose image falls on the plate. A grating is preferable, as the reduction of the spectrum is more easily made, and there is also the advantage that an ordinary picture of the object is obtained in addition to the spectrum. Practically perfect transmission gratings can now be obtained very cheaply of sufficient size to cover the lenses of ordinary cameras. If a prism is used, it should preferably be set at minimum deviation to allow of subsequent comparisons being made.

Long Focus Photographic Telescope.-Prof. E. C. Pickering some time ago asked for donations to enable a photographic lens of unusually long focus to be made for the use of the Harvard College Observatory. We hear that now the whole of the necessary amount has been subscribed by anonymous donors, and that a lens of about $\mathbf{I} 2$ inches aperture and over roo feet focal length will probably be ready for trial during the ensuing year.

Secular Perturbations of Venus.-Prof. Eric Doolittle, of the Flower Observatory, has completed his investigation of the perturbations of Venus by the computation of those caused by the planet Neptune. The perturbations arising from the six inner planets have beeh published in the Astronomical Journal, Nos. 409, 428, 418, 434, 438 and 465, and the present communication appears in No. 470 .

The planetary elements used have been adapted from Dr. G. W. Hill's "New Theory of Jupiter and Saturn."

All the equations are given in tabular form, and the variations arising from the combined action of all the disturbing planets are given in the form of six equations, one for each element.

\section{ENGINEERING PROGRESS AND PROBLEMS}

THE eighty-first session of the Institution of Civil Engineers was opened on Tuesday with an address by the president, Sir Douglas Fox. A general survey of engineering progress during the present century was given in the address, the following being a few of the points to which reference was made :-

British engineers have two chief bodies of competitors to reckon with-the engineers of the great and growing empire of Germany and those of the United States, who have been thoroughly trained in theory and practice, and are proving their ability and courage by the vast works they originate and carry out.

German and other continental engineers are greatly assisted in many ways by paternal Governments, whose officers they generally are, and who lay down valuable regulations, and in many instances establish standards of quality and design.

American engineers are encouraged by the vast demands of a comparatively new country, in which nature exists on a magnificent scale, only equalled by Switzerland and India, and of a rapidly rising civilisation calling loudly for the most recent improvements in locomotion, in building, in lighting, in telephonic and telegraphic communication.

An important matter demanding careful consideration by civil engineers, if not by the Institution itself, is whether competition in the world's race could be facilitated by the establishment, upon sufficient authority, of standard specifications for such materials as steel and cement, and the introduction of standard types for bridgework, roofing and other structures frequently occurring in practice, and for locomotives and rolling stock.

The question of the adoption of the metric system has been ably dealt with by others. I therefore only desire to record my opinion that it is of the utmost importance to the engineers and traders of this empire, that this simple and effective mode of measurement, already in force in almost every other civilised nation, should be introduced here. Having had occasion for many years to work under both systems, I can bear testimony to the great saving of time and of labour effected by the use of the metrical weights and measures, and to the ease with which the system is acquired, even by those trained to use our antiquated and complicated standards. I am strongly of opinion that the two great Anglo-Saxon nations, Great Britain and the United States, must fall into line with the rest of the world in this matter, and it would be a notable and interesting mark of our entry into a new century if, as has already been suggested to our Government, the metric system could be made compulsory as from A.D. I 900 . One great obstacle to British designs and manufactures finding their way upon equal terms through the continent of Europe and into the vast empire of China, Japan and elsewhere, would thus be removed, and engineers throughout the world would be thinking and designing upon a basis of like dimensions.

Nothing has more largely contributed to engineering successes of late years than the introduction of cheap steel of good quality and of high tensile strength, both for rails and for plates and rolled sections. Remarkable uniformity of quality has been attained, and, whilst the life of rails has been greatly increased, structures such as the Forth Bridge have been rendered practicable. At the present time mild steel is almost exclusively used for the construction of ships, thus greatly increasing their carrying capacity. Some anxiety is being caused to engineers by the manifest signs in rails and axles of fatigue after considerable wear, and the report of the Board of Trade Committee upon this subject is awaited with much interest.

With reference to this matter and to other questions involving scientific research, the resources of this Institution might, $\mathbf{I}$ suggest, be advantageously employed. Large numbers of experiments upon steel and other materials have been made with small specimens, but the testing to destruction of full-sized members of bridges and other structures, and experiments upon the effects of impact and of loads running at high speeds have been generally beyond the limits of private enterprise. As a result comparatively few of such records are available, whilst the value to our members would be very great.

There is no department of engineering which has benefited more by the inventive genius of the century than that of mining. Improved methods of sinking deep shafts, tubbing back water, and winding at high speeds from great depths, have enabled much coal to be opened up. Electricity has been impressed into the service with most beneficial results, not only of economy, but of safety and improved sanitation, and is now largely used for underground haulage, for lighting, for pumping at the face, and, in the shape of telephones, for communication. In dealing with gold and other ores, chemistry, electrolysis and mechanical engineering have combined to reduce cost and waste. Every effort is still necessary on the part of our mining engineers to face the competition, and the labour-saving appliances, not only of Belgium and Germany, but still more of the United States. It is surely to be regretted that it has been found necessary to obtain so

NO. I 567 , VOL. 6I] 
large a portion of the mining machinery for our Colonies from our Transatlantic cousins.

It seems probable that liquid air, which can now be produced at a very cheap rate, will prove a most valuable auxiliary for cooling, and thus assist in ventilating mining drifts and railway tunnels. Experiments in this direction are being made in connection with the works of the Simplon Tunnel, which are now in full activity.

The problems now opening up to the civil engineer are of surpassing importance. Trunk railways through Russia, China, Persia, Africa ; irrigation works to supply the wants of growing populations; harbours large enough to receive the vessels of the future (already eclipsing the Great Eastern, of which the chief shortcoming was that she was before her time); central installations to furnish lighting, power, traction and heating to whole counties; the extension of the telephonic communication-with and without wires; the abolition of the smoke and smell of cities; the replacement of horses by mechanical power in the streets; the increase of the speed of trains to IOO miles per hour; the erection of buildings of great height where land is valuable: the utilisation of waste products, especially the refuse of cities ; the improvement of the water-supply ; the reclamation of land; the profitable working of deep seams of coal.

These are but some of the branches in which engineering progress in the twentieth century may be expected to develop. They will call with increasing force for engineers sanguine for the future, educated upon a basis of sound scientific attainment, trained in experimental research, and qualified by practical experience-obtained, I trust, by means of that regular course of pupilage under members of the Institution which, in the less favourable circumstances of the past, has nevertheless produced the engineers who have achieved the results to which I have referred.

\section{ANTHROPOLOGY AT THE BRITISH ASSOCIATION.}

THE chief point of interest on the first day of the meeting of the Section, apart from the President's address, was a discussion on the rival systems for the identification of criminals of the Bertillon method and that based on finger-prints as propounded by Mr. E. R. Henry and adopted in British India. Mr. Henry, who is the Inspector-General of Police in the Bengal Civil Service, gave a demonstration of his system. The author referred to the importance of fixing human personality so that no efforts made to confuse it subsequently may prove availing. Of this problem the Bertillon system offered first scientific solution. But experience in India has shown that the "Personal Equation" error of measures predominates so much as to vitiate seriously the correctness of the recorded results under that system. Finger-prints, on the other hand, being absolute impressions taken from body under conditions which eliminate error in transcribing or recording, the "Personal Equation " error is reduced to a minimum. Taking the impressions of all ten digits occupies only a fraction of the time required for measuring, while search is more exhaustive and many times more rapid. This new system has been introduced on a most extensive scale throughout British India, and the Legislature has recognised it by passing an Act to amend the law of evidence so as to make relevant the testimony of fingerprint experts.

The main difficulty hitherto experienced had been that of providing an effective system of classification. But this difficulty has been overcome. A thin film of printer's ink is spread over a piece of flat tin, and each finger in turn is pressed on the film, and ifter being thus inked is pressed on paper where a clear, sharp impression is left. Fingers are impressed in their natural order of thumb, index, middle, ring, and little, those of the right hand being above, and the corresponding digit of the left hand below them.

All impressions must be either arches, loops, whorls, or composites-there is a great preponderance of loops and whorls. In primary classification arches are included under loops, and composites under whorls, and therefore, for purposes of primary classification, an impression must be either a loop or whorl. The digits are taken in the following pairs: (I) right thumb and right index; (2) right middle and right ring; (3) right little and left thumb; (4) left index and left middle; NO. 1567 , vOL. 61$]$
(5) left ring and left little finger. Taking first pair and denoting loop by $\mathrm{L}$ and whorl by $\mathrm{W}$, we get the following arrangements. Right thumb may be $\mathrm{L}$ and right index L; right thumb may be $\mathrm{L}$ and right index $\mathrm{W}$; right thumb may be $\mathrm{W}$ and right index $\mathrm{L}$; and right thumb may be $\mathrm{W}$ and right index $\mathrm{W}$. So there are four, and not more than four, arrangements possible. Similarly, in second pair, there are four such arrangements, which, taken with these of the first pair, yield 16 combinations; taking the third pair we get 64 combinations, and by adding the fourth and fifth pairs, this number rises to 256 and I024. Now I024 equals 32 squared; in other words, a cabinet containing 32 sets of 32 pigeon-holes arranged vertically would provide all the locations required. A diagram was shown how this works in practice. But the following rule is very simple. The first of each pair is shown as numerator, the second of each pair as denominator, yielding for the five sets of pairs some such formula as the following $: \frac{\mathrm{L}}{\mathrm{W}} ; \frac{\mathrm{W}}{\mathrm{L}} ; \frac{\mathrm{L}}{\mathrm{L}} ; \frac{\mathrm{W}}{\mathrm{W}} ; \frac{\mathrm{L}}{\mathrm{W}}$. A whorl in the first pair counts 16 , in the second pair 8 , in the third 4 , in the fourth 2 , in the fifth $\mathrm{I}$. No numerical value is given to a loop. Substituting these values in the formula we get $\frac{0}{18} ; \frac{8}{0} ; \frac{0}{0} ; \frac{2}{2} ; \frac{0}{1}=1 \frac{1}{9}$. Add I to both numerator and denominator and invert the fraction which becomes $\frac{20}{11}$, and this is the primary classification number, and represents that the card containing these impressions will be found on the twentieth pigeon-hole of the eleventh vertical row. The secondary classification required to break up accumulations is equally simple, and the search formula or legend for each card can be prepared rapidly without any key and brings search down to groups of very small volume.

Naturally Dr. Garson argued in support of the French system as taught by him to the English police. $\mathrm{He}$ had previously read a paper on the "Personal equation in anthropometry," and had fully described the well-known Bertillon system; he admitted there was always a margin of uncertainty in measurements, but denied that it need be so large as Mr. Henry asserted. He expressed regret that the Indian Government had abandoned the Bertillon system for one based solely on finger-prints.

A paper, also illustrated by lantern slides, was read by Francis Galton on "Finger-prints of young children," in which he demonstrated that clear prints of all ten fingers of a baby would suffice for after-identification by an expert, but by an expert only. Although new ridges may appear in infantile life the type of each pattern persists all through life, and is never doubtful to a practised eye.

The whole of Friday was devoted to samples of the work accomplished by the Cambridge Expedition to Torres Straits and New Guinea. Dr. A. C. Haddon, the organiser and leader of the expedition, led off with a short report on the work done (cf. NATURe vol. lx. p. 4I3), and illustrated with lantern slides the physical character of the inhabitants. A communication on the linguistic results of the expedition, by Mr. Sidney H. Ray, was laid before the Section.

The language of the Eastern tribe of the Straits bears no resemblance to the Melanesian, and but little to the Australian group of languages, while that of the Western tribe is decidedly of the Australian type. Most of the coast languages of the Port Moresby and Hood Bay districts are very closely akin to the languages of the Melanesian Islands, except some, such as the Koitapu, Koiari and Cloudy Bay dialects, which approach the Australian type, but has nothing in common with the Melanesian. Mr. C. S. Myers gave an interesting paper on savage music, based on his observations in Murray Island and Sarawak.

As our modern orchestra admits the noises of drums and cymbals, and our harmony allows chords which in a more classical period were inadmissible, we, in our inquiry into past and primitive music will not refuse to consider certain sounds as musical even though they be noisy. Sympathy should be our sole test of music. In savage life the songs of a tribe are its chief heritage. Certain songs recorded on the phonograph in Murray Island, Torres Straits, are now obsolete, and will probably die out with the old men. Neither there nor in Borneo could any trace of the notes of birds be found in the music. Of the two fundamentally distinct elements in music, rhythm and melody, the one has its basis in bodily movement, the other in the enotional recitative. In Murray Island the drum is beaten to accentuate the words of the old songs, the music being singularly lacking in rhythm; among the North American Indians, on the other hand, rhythm is well developed. The 